\title{
Factors Affecting Implementation of Community Projects: Case of Kimira - Oluch Smallholder Farm Improvement Project in Homa Bay County, Kenya
}

\author{
Collins Odoyo \\ Euro Apex Investment, Homa Bay County, Kenya \\ *Corresponding Author: odoyo08@yahoo.com
}

Copyright $@ 2013$ Horizon Research Publishing All rights reserved.

\begin{abstract}
This paper assessed the factors affecting implementation of community projects At Kimira - Oluch Smallhaolder Farm Improvement Project (KOSFIP) in Homa Bay County, Kenya. Study objectives included assess the factors causing delay in implementation of KOSFIP project; assess the factors causing escalation of costs in implementing KOSFIP project assess the attitude of the community towards KOSFIP project; and assess the effect of community leadership on implementation of KOSFIP project. A case study research design was used to collect data from 3,000 households in the project's area of coverage. The study established that: natural occurrences such as floods and daily coordination of activities were major causes of delay as supported by $57.9 \%$ and $56.2 \%$ of the respondents respectively. Similarly, demand for compensation and resettlement, mitigation of floods and inflationary fluctuations were the major factors of cost escalation as supported by $59.6 \%, 49.7 \%$ and $57.5 \%$ of the respondents respectively. However, there was minimal interference with project implementation from the community as $93.7 \%$ of the respondents felt that community members were not a hindering factor. Finally, there was a weak positive linear relationship between local leaders support for implementation of KOSFIP project and their strong belief in handouts as shown by $\mathrm{R}=0.421$ and reduction in variations of $\mathrm{R}^{2}=17.8 \%$ in implementation of KOSFIP project can be explained by local leaders belief in handouts. Further, the value of $\mathrm{t}=5.168$ and 6.319 indicates that there was a strong significant positive effect on implementation of KOSFIP project by leaders' belief in handouts. The study is useful to project planners, stakeholders and financiers who are in need of relevant information on factors affecting project implementation. It will also be useful to researchers and scholars who wish to generate more knowledge or fill gaps on implementation of community projects.
\end{abstract}

Keywords Project Implementation, KOSFIP, Cost Escalation, Community Leadership, Homa Bay County

\section{Introduction}

Kimira-Oluch Smallholder Farm Improvement Project (KOSFIP) is a rural community development project in Homa Bay County of the former Nyanza province of Kenya that was set up and funded by the Government with the overall aim of improving the livelihoods of smallholder farmers by enhancing their incomes through practice of sustainable irrigated agriculture. It was rolled out by the Ministry of Regional Development Authorities (MORDA) in February 2007. The project was initiated in a region with a backdrop of extreme poverty of above $56 \%$ amongst its dense population who experienced unreliable rainfall and frequent crop failures where agriculture is the mainstay of the people (Poverty Mapping exercise, 2003/2004). Over-arching and instructive to this flagship project is the government's national development agenda focusing on economic growth and poverty reduction subsumed in strategic policy papers namely- Poverty Reduction Strategy Paper (PRSP), Economic Recovery Strategy for Wealth and Employment Creation (ERWEC) and Strategy for Revitalizing Agriculture (SRA). The project would also contribute to the achievement of core Millennium Development Goals (MDG) objectives and those of the New Partnership for Africa's Development (NEPAD) initiative. Thus the project would kill two birds with one stone by increasing irrigated agricultural-based incomes for farmers in such an environment while helping to secure the overall goal of national development.

It was envisaged that the project would cost Ksh.3.15 billion (UA 27.77 million) in 2005 composed thus: loan and grant from the African Development Bank (ADB) 86.89\%, GOK contribution $11.35 \%$ and beneficiaries in kind contribution $1.76 \%$. The project's stated outputs were; the development of two irrigation schemes covering about 1,474 ha of irrigated land and with about $88 \mathrm{~km}$ of feeder roads constructed, which were entirely farmer-managed; the establishment of two fully incorporated farmers' organizations to own and trained to efficiently manage the 
schemes; and the provision of extension and market services to give training to farmers in entrepreneurial skills, good crop husbandry practices, quality control and irrigation system management.

\section{Literature Review}

Since time immemorial human civilizations have used various types of projects to deliver change or benefit to societies. They include the projects such as Voyages of Discovery of Henry the Navigator, the Great Pyramids of Egypt, the ancient Roman roads, the Grand Canal of China, the Dykes of Holland and the Atomic bomb among others. Since 1950s the development agenda has been characterized by projects and programs aimed at improving the quality of life of beneficiary communities, be it in physical or qualitative terms (Chikati, 2009: 5).

Projects of antiquity have left their mark on society and contributed to positive changes that benefit society in general and improved living conditions for many people (Cleland and Ireland, 2007). The nature of projects is that they vary in scale, purpose and duration. Projects represent the commitment of human and physical resources to produce specific outputs in a given time and budget framework. They may be initiated by a community requiring modest inputs and producing tangible outputs within a relatively short timeframe. At the other extreme, projects may require substantial financial resources and only generate benefits in the long term. Projects may stand-alone or be integrated into a program, with several projects contributing to one overall goal. Despite the difference in the nature of projects, aspects of sound project implementation and management are universally shared by them (Chikati, 2009: 7).

Before the Second World War the main emphasis in the development of tropical countries was on communications and material resources. There was much less emphasis on small-scale development specifically related to the needs and welfare of the people in their local communities. Today the governments of most tropical countries are aware of the need to foster development in local communities as well as nationally and actually have special programs to stimulate and help communities to improve their livelihoods. These are known as community development programs or projects. Such programs are not limited to the national governments but have become the main concern of several intergovernmental agencies such as UNESCO or USAID, and a wide variety of local community-based organizations (CBOs). Thus the field of community development includes any action by any agency and primarily designed to benefit the community (T.R. Batten, 1957).

Christenson (1989) identified three different community approaches: self-help, technical assistance and conflict. This typology is useful for understanding some of the ways practitioners or project implementers approach their work. Self-help assumes that increasing the capacity of residents to address their problems will result in improvement in quality of life and ability of residents to help themselves in future. Technical assistance approach adopts a belief that the most important obstacle communities face concerns the lack of technical knowledge and information to surmount their problems, and the quality of life will improve if the community is given such technical assistance. Conflict approach advocates that the fundamental problem a community faces are the lack of power to overcome and if they are organized around the problem identified the community will win (Green and Haines, 2008).

Community development requires the involvement and participation of local residents in identifying the strategies they wish to use to improve their quality of life. Participation is seen as developmental, educative, and integrative and as a means of protecting freedom (Robert, 2004). One of the key assumptions of participation is that local residents will be more supportive of the project, and therefore increase the likelihood of its success, if residents have input in the decision-making process. Also, local residents probably have a better knowledge about assets and needs of the community. Finally, public participation is considered the centre-piece of the democratic process. One of the distinguishing characteristic of community development is that it involves the creation of local organizations (CBOs) to help build assets. These organizations offer several advantages for carrying out place-based programs as they have extensive contacts and information about the neighborhood. They are also controlled by local residents (Green and Haines, 2008).

Most, if not all, projects go through a life cycle which varies with the size and complexity of the project. The life cycle for medium to large projects will generally follow the pattern set out in BS6079: conception, feasibility, evaluation, authorization, implementation, completion, operation and termination (Albert, L. 2007:37).

In identification one project idea out of several is chosen and defined. Feasibility comprises tests for technical, commercial and financial viability, technical studies and investment appraisal plans are made. Evaluation includes application for funds, stating risks, options and TCQ criteria. Authorization comprises of funds approvals, permits, conditions and project strategy. Implementation includes development design, procurement, fabrication, installation and commissioning. Completion includes performance tests, hand-over to client and post project appraisal. Operation includes revenue earning period, production and maintenance. Project termination includes close-down and decommissioning and disposal.

Projects go through a life cycle to completion, hopefully on time, within budget, and satisfying the technical performance objective. As they progress to completion they transform project resources to a product, service or organization process. When completed, the project joins an inventory of capability provided by the organization that owns the project (Cleland and Ireland).

Implementation is the execution of planned activities 
which converts human and physical resources into a product or service of value to the customers. It is should be noted that if the operational systems are not clear then the implementation process will have a rocky path and the project might fail to realize the intended goal or purpose. The way in which the project is implemented can have a significant impact on whether it will be successful or not.

Project implementation is a complex process usually comprising of multiple variables which influence implementation including resources management, the operational systems, the organizational culture and the leadership of the organization.

Projects are designed, planned and implemented in tandem with the sequence displayed by the project cycle. The Log Frame is the specific planning tool that is used to design, appraise, manage, monitor and evaluate the passage of a project through the project life cycle from policy framework to final evaluation. It presents the objectives-related activities and corresponding assumptions and pre-conditions of the project design of different hierarchical level matrix format (Chikati, 2009).

Projects are often initiated in the context of a turbulent, unpredictable and dynamic environment (Jeffrey and Dennis, 1987). Many projects, therefore, are usually bedeviled by challenges, constraints and risks as they are execution through completion. Consequently, despite the significant input of human and financial resources, many fall short of expectation. Many failed to meet the priority needs of target beneficiaries, costs escalated, stated outputs were not achieved or if achieved were not sustained, implementation dates slipped by or adverse outcomes were not anticipated.

Projects are influenced by a multiple of factors which can be external or internal to the organization responsible for its management and execution. These include poor project management, inadequate opportunities for potential beneficiaries to participate in project identification and design, poor linkages between project activities and project purpose, insufficient attention to external environment during project design, among others. It has also been recognized that projects were likely to succeed when account was taken of socio-economic context in which they operated (Batten, 1957). The important thing for the project manager is to recognize what these factors are and how they impact on the project during the various phases from inception to final hand-over, or even disposal.

The external or internal influences are known as the project environment. The external factors making up this environment are the client (customer), consultants, contractors, suppliers, competitors, politicians, national and local government agencies, public utilities, pressure groups, the end users and the general public. Internal influences include the organization management, the project team, internal departments, and stakeholders. All these influences are neatly encapsulated by the famous acronym PESTLE.

Politics manifests itself in all organizations as opinions and attitudes of the different stakeholders in these organizations. In addition, the stakeholders relied upon by the project may also have their own agenda and preferences for participating in the project. The relationships to the project by these stakeholders can vary from very supportive to antagonistic, but depending on their field of influence, must be considered and managed. However, neither the sponsor nor the project manager has control over external politics such as political turmoil which may disrupt the project.

Economic influence has two levels: first, the internal economics principle relating to the viability of a project holds that unless there is a net gain there is no point in even considering embarking on a project. The external or macro-economic relate to high interest rates and prices, tariff barriers, embargoes and shipping restrictions, among other influences, of which the project manager have no control over.

Many projects, and indeed most construction projects, inevitably affect the communities in whose area they are carried out. Conversely, the opposite holds true that the benefitting communities also affect projects being rolled out in their areas. It is vital therefore to inform the residents in the affected areas as early as possible of the intent, purpose and benefits to the community of the project. Some projects cannot be started until after a public inquiry, environmental impact assessment, route survey or lengthy planning procedures.

It goes without saying that unless a project is technically sound it will end in failure. The technical requirements have to be firmed up at an early stage after a rigorous assessment of all realistically available options. Each option may then be subjected to a separate feasibility study and investment appraisal to ensure the project will achieve the stated technical performance goals.

One of the fundamental requirements of a contract, and by implication a project, is that it is legal. In other words if it is illegal in a certain country to build a brewery, little protection can be expected from the law. The relationships between the contracting parties must be confirmed in a legally binding contract which complies with the law and preferably the customs of the participating organizations. The project context includes the established conditions of contract and other standard forms and documents used in industry.

The location of the project clearly has an enormous influence on the cost and completion time. The same type of project can be constructed in various locations but the problems, costs, and construction times can be very different. Some considerations to be taken into account when deciding to carry out a project in a particular area include; temperatures, rainy seasons, transport infrastructure, power supply, soil types and quarries among others.

Almost any person or organization with an interest in a project can be termed a stakeholder. Each project has its own unique set of stakeholders. The type and interest of a stakeholder are of great interest to the project manager since they enable him to use these to the greatest benefit of the 
project. It is therefore important that he carries out a stakeholder analysis to list, classify and assess the influence of the stakeholders (Albert, L. 2007). The view point of every stakeholder should be considered (Cleland and Ireland, 2007).

The effect of the attitudes of the community and its leadership on implementation of projects is vividly captured by Busiinge C. (2010) his research publication 'The Impact of Donor Aided Projects through NGOs on the Social and Economic Welfare of the Rural Poor'. He reports that interviews with the NGO staff revealed that the communities don't own the projects that they implement and unless there was money they did not want to participate. Projects also seemed to have created the impression that nothing can work without money. Some of local leaders complained that people no longer attend their meetings because they did not have the allowances. As a result of this, some of the leaders and community members did not want to attend meetings of project activities and that was affecting the ownership of the projects and the work of local leaders. It was also emerging from interviews with communities that projects often undermined what people know and they participate for formality reasons and not because they believed in the project (Busiinge, 2010).

The rationale of addressing socio-economic and gender issues in project implementation is the wish to achieve sustainable development. Projects should identify and understand the different roles and entitlements between men and women in the target communities, and the special challenges faced by disadvantaged groups (Chikati, 2009: 5).

On local leadership, Busiinge advises that they have an important role to play and can therefore not afford to sit back and watch as projects crumble. While the NGOs in Uganda have played an active role to monitor the performance of government programs, local leaders need to step up their efforts to monitor the implementation of NGO projects as well. There was need for the governments to create and participate in information sharing platforms to discuss development progression in their communities. That away, the collaborators keep watch of each other's performance and accountability in community development programs.

To manage a project the client usually sets up a project organization which can supply the resources for the project and service it during its life cycle. For a large project this set up would comprise of a project steering committee and a project office.

The Project Steering Committee (PSC) acts as a supervisory authority during the life cycle of the project. Its job is to ensure that the interests of the sponsoring organization (or client) are protected and that the project is run and delivered to meet the requirements of these organizations. It makes this body appoints the project manager who reports to it on regular basis on the progress of the project. The PSC should also be consulted or required to make decisions and policy declarations on major issues. The project office, usually headed by a project manager, is almost mandatory for project administration in large projects. The functions most usually carried out by the project office include the preparation of project schedules, progress reports, project costs and quality reports and operations management among others. It monitors the consultancies engaged by the project to deliver on specific activities to ensure that the expected deliverables produce the specified benefits. Often the typical project manager has responsibility for successful project outcomes without sufficient power, budget and manpower to handle all of the elements essential for project success. In addition, projects are often initiated in the context of a turbulent, unpredictable and dynamic environment (Jeffrey and Dennis, 1987).

The government plays a pivotal role in community development projects' funding, initiation, implementation and overall management. It provides the enabling policy and legal environment for the regulation of finance and the procurement of goods, works and services. CBOs and NGOs and their activities are regulated through legal mechanisms devised by the government. Government policy to NGOs is wide ranging and depends largely on political factors within a country, and may be repressive or supportive (Green and Haines, 2008, p265). The government may create the need to participate in information sharing platforms to discuss development progression in their communities. Their representatives keep watch on the performance of community development programs. Ideally local governments need to demand for NGOs' accountability (Busiinge, 2010).

At the broad level, multilateral aid organizations, such as the World Bank and IMF, focus on central government financing and very large infrastructure projects. However, other organizations, notably international NGOs such as CARE, World Vision and Oxfam, also target community development projects that aim to help communities raise their quality of life (Green and Haines, 2008, p265). Private investment by large entrepreneurs in local projects has also become significant as noted by Ms Elumelu, after his holding company purchased Ughelli Power Plant in Nigeria: "The investment we are making demonstrate our intent to become a significant player in the power sector. It also shows in a clear and meaningful way that African capital should be part of the solution to African challenges. We need more of Africa's companies to step up and get involved in Africa's development", (Today in Business, The Standard, $4^{\text {th }}$ July 2013).

Most donors attach various restrictions to their funding including, among others, sound financial management systems in place, good leadership with integrity, educated staff with experience and the strategic plans of the organization. Organizations lacking these ingredients have difficulties attracting donor funding. Some donors will first assess the capacity of the organization's systems and structures to handle funds before funding can be approved. They also consider if the potential recipient has experience and knowledge to meet deliverables (Ali, 2012).

Many donors give their support for the satisfaction of making a difference and so implementers should describe the 
return on their investment in quantifiable terms, clearly specifying who will benefit from their generosity and how(Rotary International).

Cultivating a close relationship with donors can lead to increased project funding for a prolonged duration of time. Donors need to be provided with regular reports on the use of donated funds. They appreciate knowing how donations are being used, and it's in the project's best interest to be as transparent and accountable as possible with project funds. Also, donors should be kept informed of the project's progress, and be invited to participate in project events and celebrations (Rotary International).

Donated goods and funds can make a tremendous impact on a community project. But it should be remembered that projects should be needs-driven and not supply-driven. "When your organization identifies the need for specific donated goods, reach out to the local community first. Purchasing goods locally may be less expensive than having them shipped but it helps support the local economy. If you decide to accept goods from an international partner, be sure that all parties understand, and are prepared to meet, the relevant customs regulations, procedural requirements, and shipping costs" (Rotary International). Thus most donors impose stringent rules and regulations for procurement of goods, works and services.

The success or failure of a project is directly related to its goals and objectives which form the baseline to measure the degree of success or failure. However, there is no simple success or failure of a project because successes do not meet all stakeholders' expectations and failures provide some benefits albeit perhaps at a cost that is more than expected (Cleland and Ireland, 2007).

Cleland and Ireland asserts the conventional criteria for project success are established from three business requirements of a well managed project namely: cost, schedule and technical performance, all of which remain the same through completion for a stable project. However, a stable project, where there is no migration of goals and objectives, was a rare scenario while projects that 'grow' in requirements and 'discovered' work may be the norm. Cleland and Ireland further noted that a fourth criterion may exist such as safety which was considered equally important for certain industries like airlines.

A project is generally considered to be successfully implemented if it: comes in on-schedule (time criterion), comes in on-budget (cost criterion), and achieves basically all the goals originally set for it (effectiveness criterion) and, is accepted and used by the client for whom the project is intended (client satisfaction criterion). By its basic definition, a project comprises of a defined time frame to completion, a limited budget, and a specified set of performance characteristics. Further, the project is usually targeted for use by some client (Jeffrey and Dennis, 1987).

Variances budget and schedule need to be investigated to see what is causing the adverse situation. Trends and variances alert decision makers but do not necessarily dictate corrective action (Cleland and Ireland, 2007).
Delays in construction according to Acharya, Lee, Kim and Lee (2006) may be caused by the client, the contractor, the consultants, acts of God, or a third party and they may occur early or late in the job. In whatever cases, negotiating a fair and timely damage settlement is beneficial to all parties (Bushbait and Cunningham, 1998). Thus the ascertainment of the period of project delay serves as basic information from the appointment of responsibility, which may be a highly complex operation in cases with concurrent causes. In this respect, when a delay claim occurs, it is very important to assign responsibility and magnitude to delays, and it is often difficult to analyze the ultimate liability in delay claims (Kraiema and Dieknam, 1987).

Ozdemir (2010) asserted that the construction industry has a very poor reputation for coping with delays. Delay analysis is either ignored or done subjectively by simply adding a contingency. As a result many major projects fail to meet schedule deadlines. In a construction project where time truly equals money, the management of time is critical (Duran, 2006), thus predicting the likelihood of schedule delay may play a key role towards project success (Luu, Kim, Van Tuan, and Ogunlana 2009).

A project's success is not always determined by its duration. Projects that last a long time generally require more planning and involvement from club members, so it is important to discuss in advance how much time members are willing to commit. Setting realistic goals will help ensure that the project can be completed effectively (Rotary International).

There is a fear that obstacles in the planning and implementation phases translate into cost escalation, if they do not block projects altogether (Ardity, Akan and Gurdamar 1985, Morris and Hough 1987, Snow and Dinesen 1994, Chan and Kumaraswamy 1997). Both the research literature and the media occasionally claim that the track record is poorer for larger projects than for smaller ones and that cost escalations for large projects are particularly common and especially large (Merewitz 1973: 278; Ellis 1985; Morris and Hough 1987: 1, 7).

\section{Methodology}

This study adopted a case study research design where primary data were collected from selected sample through questionnaires and interview of Key Informants. This research design was preferred because it enabled the researcher to collect in-depth data from administering well prepared questionnaires and reinforcing them with interview schedules with key informants from KOSFIP project offices. Simple random sampling technique was employed to arrive at a sample of 384 individuals from a population of 3,000 households as at the time of the research. Both the primary and secondary data were used and analysis was done through the frequency distribution, correlation and regression analysis techniques.

The study was limited to Kimira-Oluch Smallhoder Farm 
Improvement Project (KOSFIP) in Homa Bay County, Kenya. The study was to assess the factors that affect implementation of community projects.

\section{Discussion}

The results from the study show that the there are a number of factors that caused delay in implementing KOSFIP project. First and foremost, it was found out that floods and other natural occurrences delayed the implementation of KOSFIP project to some extent. A total of $57.9 \%$ of the respondents agreed to this fact that mitigating damages caused by floods delayed project implementation. Only $23.4 \%$ of the respondents disputed this opinion, while $17.4 \%$ were indifferent. This state that natural occurrences such as, floods ought to have been catered for during the planning phase in terms of time and other resources.

The study also established that coordination of daily activities and duties by the implementing agency contributed to the delay in implementation. A total of $56.2 \%$ of the respondents in this study supported this statement. However, there for a very slim difference between the numbers of those who supported the delay attributed to delayed launching time were $31.5 \%$ with $52.1 \%$ disagreeing and $16.4 \%$ somewhat agreeing. Looking at this result, delaying the implementation start period was not a strong factor in delaying the overall implementation of KOSFIP project. Further the study found out that there were no stoppages of construction by the community members that would have attributed to another factor causing delay in project implementation.

The study also established that there were several factors leading to cost escalation in implementing KOSFIP project such as community demands for compensation and resettlement, inflationary fluctuations of money, frequent variation of construction contract recommended by the project implementers and mitigation of floods and other natural occurrences.

It was established that some of the members of the community that were not included in the initial project budget were demanding for compensation and resettlement by the project. This led to the project cost being escalated as a result of trying to meet the demands of such individuals. From the findings, $59.6 \%$ of the respondents agreed to this statement with only $26.8 \%$ disagreeing. This was corroborated by key informants who revealed that at design of the project only 24 houses were to be built for those adversely affected by irrigation infrastructure, but 71 additional houses were finally demanded and built by the project for claimants.

The study further established that inflationary fluctuations of money value from the time feasibility study was conducted and budgeting and planning carried out to the actual implementation period, there were variations in money values. This affected the cost of implementing KOSFIP project. As found out from the opinion of the respondents to this study, $57.5 \%$ agreed to this statement, while only $22.4 \%$ of the respondents disagreed to this opinion, with $20.1 \%$ somewhat agreeing. This was corroborated by key informants who revealed that the design of the project was in 2004 and by tendering in 2008 the project was forced to shelf some component outputs for lack of sufficient funds.

It was further established that frequent variation of construction contract recommended by the project implementers was another factor that led to cost escalation. A number of variations that were being made on the initial project plan from time to time by the project contractor with recommendations from KOSFIP project implementers had a great effect on the project cost. Thus $47.4 \%$ of the respondents agreed to this statement while $36.7 \%$ denied this statement, with $15.9 \%$ somewhat agreeing. This was corroborated by key informants who revealed that indeed there were far reaching variations including; reinforced concrete canal lining at Kshs. 400million and three extra bridges and $7 \mathrm{~km}$ access road all valued at Kshs. 175 million.

Natural occurrences such as flooding were yet another factor that led to cost escalation. Since the planning and budgeting phase never anticipated floods to interfere with implementation and thus never budgeted for them. Mitigating such occurrences whenever they occur, strain the budgetary allocation for KOSFIP project implementation. From the study findings, $49.7 \%$ of the respondents agreed to this opinion, while $32 \%$ disagreed with $18.2 \%$ somewhat agreeing as seen in table 1 above. This was corroborated by key informants who revealed that the project compensated the contractor to rehabilitate installations and equipment swept away by the floods to the tune of Kshs. 400million.

However, the study never established vandalism of equipment or issues of cultural beliefs of the community as factors that impacted on KOSFIP project cost.

On overall $93.7 \%$ of the respondents declined the statement that community members never supported the implementation of KOSFIP project, $1.3 \%$ somewhat agreed while only $5 \%$ agreed with the statement. This gives a strong indication that community members were not a contributing factor in the delay in implementation of KOSFIP project.

In the other case, local community in the study area were not affected by the influence of handouts as the study found out from the respondents of the study. $74.2 \%$ of the respondents did not agree with the statement that local community needed to be influenced with handouts so as to fully support the implementation of KOSFIP project. 10.4\% were non committal, while $15.4 \%$ agreed with the statement. This further indicates that local community were not in any way a hindrance to implementation of KOSFIP project.

Further on looking at the perception that the local community perceived KOSFIP project as a government initiative that was never to benefit them, $72.7 \%$ of the respondents disagreed while $15.9 \%$ were somewhat agreeing and $11.5 \%$ of the respondents were in support of the statement. On looking at fear of losing land to the project, the trend was however still the same as $65.9 \%$ of the respondents disagreed with the statement, $16.9 \%$ were non committal 
while, $17.2 \%$ supported the statement as being true.

Looking at all these, it is an indication that there were no contributions from the community with regards to contributing to the delay in implementation of KOSFIP project. The study found out that community leadership embraced KOSFIP project implementation. The study findings indicated that a total $97.1 \%$ of the respondents were of the opinion that local community leaders were in support of KOSFIP project implementation, $1.6 \%$ were non committal while, $1.3 \%$ felt that local leaders never supported the project implementation.

On further analysis to determine the relationship between local leaders support for KOSFIP project and strong belief on handouts and fear of losing their authority to project leaders in order to support project implementation, the study established that $R$ was equal to 0.421 , and $R^{2}$ being 0.178 as summarized in table 1.

Table 1. Relationship between local leaders' belief in handout, losing authority and their support to project

\begin{tabular}{ccccc} 
Model & $\mathrm{R}$ & $\mathrm{R}^{2}$ & Adjusted $\mathrm{R}^{2}$ & $\begin{array}{c}\text { Std. Error of the } \\
\text { Estimate }\end{array}$ \\
\hline 1 & 0.421 & 0.178 & 0.173 & 0.573
\end{tabular}

From table 1 above, it implied that there was a weak positive linear relationship between local leaders support for KOSFIP project implementation and their strong belief in handouts. Further $\mathrm{R}^{2}=0.178$ which can be expressed as $17.8 \%$ and indicates variations in implementation of KOSFIP explained by local leaders being affected by a strong belief in handouts, and being threatened of losing their authority to community project leaders. Further looking at the table below $\beta=0.292$ and 0.179 , and $t=5.168$ and 6.319 . The $t$ values indicate a strong significant positive effect on KOSFIP project implementation by the two variables.

The study also established that government and donor guidelines and procedures also had greater impact on the implementation of KOSFIP projects as stated by the key informants for the study. Intensive dependency on consultancy was also found to have contributed to delay in realization of project out.

\section{Conclusions}

In conclusion, the study established that there were a number of factors that caused delay in implementation of KOSFIP project. Factors such as natural occurrence for example, floods that were not anticipated during planning of the project but had to be mitigated, coordination of daily activities by the project implementers, topped the list. However the study did not found out stoppages of construction by community and vandalism of the project equipment by the community. This therefore was an indication that, they were never contributing factors in delaying implementation of KOSFIP project.

Coming to cost escalation, the study established that, mitigation of floods that was not initially budgeted for consumed part of the project's money leading to escalation of cost. Also there were demands by community for compensation and settlement, some of which were not initially covered by the project's budget. This means that feasibility studies always need to be comprehensive to minimize such challenges. Inflationary fluctuations in the value of money between the period of feasibility study and implementation period was also responsible for cost escalation. This calls for immediate implementation of any project after the feasibility study is completed.

Moving to community attitudes towards KOSFIP project, the study established that there was minimal negative influence by the community, an indication that most community members welcomed the project and as such, they were supporting its implementation. Further the study revealed that they clearly understood the aims and objectives of the project and did not perceive the project as government initiative with limited benefit to them nor as a project that intended to deprive them of their pieces of land.

The study further established that community leadership embraced KOSFIP project implementation and did not look at it as an avenue where they would lose their authority to project leaders. The study also found out the leaders in KOSFIP project locality are not affected by strong belief in handout that normally affects leaders' judgments in other localities, this seen from the weak positive association displayed by the analysis.

Finally, KOSFIP project implementation was further found to be affected by the numerous government and donor guidelines and procedures. Intensive dependency on consultancy was also found to have contributed to delay in realization of project out.

I agree with Jeffrey and Pinto in their work on critical success factor in effective project implementation who aptly concluded that projects are often initiated in the context of a turbulent, unpredictable and dynamic environment.

The study indicated possible directions for future research. First, there is need to conduct extensive and comprehensive surveys to document the communities' attitude towards the projects implemented by the Kenyan Government and establish if they fully embrace them for their benefits. Secondly, there is need to establish the degree of local leadership support. Thirdly, there is need to investigate the impact of community project on community livelihoods. Finally, there is need to establish the efficacy of the increased use of consultancies by the government in delivering certain outputs at high cost during community project implementation.

\section{REFERENCES}


[1] Acharya, N. K., Lee, Y. D., Kim, S. Y. \& Lee, J. C. (2006), Analysis of Construction Delay Factor: A Korean Perspective, Proceedings of the 7th Asia Pacific Industrial Engineering and Management Systems Conference, 17 - 20, December, Bangkok, Thailand.

[2] Albert, L. (2007), Project Management, 'Planning and Control'

[3] Ali I. A. (2012), Factors influencing sustainable funding of non-governmental organizations in Kenya: a case study of sisters maternity home (simaho) in garissa, University of Nairobi

[4] Ardity et al (1985), San 'Cost Overruns in Public Projects', International Journal of Project Management vol. 3, no. 4, pp. 218-225.

[5] Batten, T.R.(1957), Communities and Their Development.

[6] Bushbait, A. A. \& Cunningham, M. J. (1998), Comparison of Delay Analysis Methodologies. Journal of Construction Engineering and Management, 315-322.

[7] Busiinge C. (2010), The Impact of Donor Aided Projects through NGOs on the Social and Economic Welfare of the rural poor

[8] Chan, Daniel W. M. and Kumaraswamy, Mohan M. (1997), 'A Comparative Study of Causes of Time Overruns in Hong Kong Construction Projects', International Journal of Project Management, vol. 15, no. 1, pp. 55-63.

[9] Chikati, J. (2009), Project Cycle Management, 'An Integrated Approach and Logical Framework'.

[10] Christenson, J.A. (1989), 'Themes of Community Developm ent'.

[11] Dennis P. Slevin \& Jeffrey K. Pinto (1987), Critical Success Factors In Effective Project Implementation.

[12] Duran, O. (2006), Current risk management applications in Turkish construction industry, an unpublished Master thesis, Gaziantep University, Gaziantep.

[13] Ellis, W. (1985), 'Welcome to a New White Elephant', Financial Times, 17 August, 1985.
[14] Green, P.G. \& Haines, A. (2008), Asset Building\& Community Development.

[15] Jeffrey K. Pinto \& Dennis P. Slevin (1987), Critical Success Factors in Effective Project Implementation

[16] KOSFIP Appraisal Report (2006), http://www.afdb.org/filea dmin/uploads/afdb/documents/project-and-operations/ke-200 6-022-en-adf-bd-wp-kenya-appraisal-report-kimira-oluch-sm allholder-farm-improvement-project.pdf

[17] Kraiema, Z.M. \& Dieknam, J.E. (1987), Concurrent Delays in construction project Journal of Construction Engineering and Management, 113(4), 591-602.

[18] Luu, V., Kim, S., Van Tuan, N., \& Ogunlana, S. (2009). Quantifying schedule risk in construction projects using bayesian belief networks. International Journal of Project Management, 27, 39-50.

[19] Merewitz et al (1973), Cost Overruns in Public Works, Benefit-Cost and Policy Analysis Chicago: Aldine Publishers, pp. 277-295;

[20] Morris, Peter W. G. and Hough, George H. (1987), The Anatomy of Major Projects: A Study of the Reality of Project Management, New York: John Wiley and Sons.

[21] NGO Co-ordination Act (1990),http://www.usig.org/country info/laws/Kenya/Non-Governmental_Organizations_Coordi nation_Act_1990_Kenya_\%20.pdf

[22] Ozdemir, M. (2010), A probabilistic schedule delay analysis in construction projects by using fuzzy logic incorporated with relative importance index (rii) method. A thesis submitted to the graduate school of natural and applied sciences of Middle East Technical University.

[23] Rotary International Guide, http://www.rotary.org/ridocume nts/en_pdf/605a_en.pdf

[24] Snow, Peter and Dinesen, Betzy, (1994) Beyond 2000: a Source Book for Major Projects England: Major Projects Association.

[25] The Standard (4th July 2013), Today in Business 